\title{
Retrospective evaluation and prediction of clearance and toxicity of high dose methotrexate in childhood acute lymphoblastic leukemia patients
}

\author{
Yuxia Shan ${ }^{1}$, Hui Gao ${ }^{2}$, Zhong Li ${ }^{\oplus 1}{ }^{*}$, Jinghua Li ${ }^{1}$, Yang Liu' ${ }^{1}$ Lujuan Li ${ }^{1}$, Qi Zhang1 \\ ${ }^{1}$ Respiratory Ward, Dalian Children's Hospital, Dalian City, China, \\ ${ }^{2}$ Hematology Ward, Dalian Children's Hospital, Dalian City, China
}

\begin{abstract}
To find the predictors of High Dose Methotrexate toxicities in childhood Acute Lymphoblastic Leukemia Patients. This study included 198 Childhood Acute Lymphoblastic Leukemia patients (303 infusions) who were treated with High Dose Methotrexate. Methotrexate levels at different time point were measured by modified enzyme multiplied immunoassay technique assay. The correlation between Methotrexate levels and toxicity was evaluated by Receiver Operating Characteristic curve. When the Methotrexate level at $42 \mathrm{~h}$ was lower than $0.76 \mu \mathrm{mol} / \mathrm{L}$, the sensitivity for predicting thorough clearance at $66 \mathrm{~h}$ was $90.78 \%$. When the Methotrexate level at $42 \mathrm{~h}$ was higher than $1.5 \mu \mathrm{mol} / \mathrm{L}$, the sensitivity for predicting delayed clearance was $82.17 \%$. When the Methotrexate level at $66 \mathrm{~h}$ was higher than $0.5 \mu \mathrm{mol} / \mathrm{L}$, the sensitivity for predicting Methotrexate toxicity was $89.09 \%$. When the Methotrexate level at $66 \mathrm{~h}$ was lower than $0.1 \mu \mathrm{mol} / \mathrm{L}$, the sensitivity for predicting Methotrexate nontoxicity was $92.73 \%$. The Methotrexate level at $42 \mathrm{~h}$ could be predictor for delayed clearance. The Methotrexate level at $66 \mathrm{~h}$ could be predictor for toxicity.
\end{abstract}

Keywords: Childhood acute lymphoblastic leukemia. High dose methotrexate. Toxicity. Leucovorin rescue.

\section{INTRODUCTION}

Now childhood Acute Lymphoblastic Leukemia (ALL) cure rates have exceed 80\% (Bouquie, Deslandes, Bernaldez, 2013; Pui, Evans, 2006). This was partly due to the use of High Dose Methotrexate (HDMTX), an important component of the treatment protocol(s). MTX has serious and sometimes life-threatening toxicity which could be avoided by following special precautions during HDMTX administration and post-treatment management. The general approach of avoiding MTX toxicity include leucovorin rescue, adequate hydration, urine alkalization, however, all of the regimens was indicated by monitoring MTX level at fixed time points.

*Correspondence: Z. Li, Dalian Children's Hospital, No.154, Zhongshan Road, Xigang District, Dalian City China, Zip Code, 116012. Tel: 086-041183770636. E-mail: 15998650850@139.com
The time and dosage of leucovorin rescue are critical, plenty of convincing evidence had proved over-rescue of leucovorin may cause relapse. But the possible damage or death caused by MTX toxicity plus the following legal and financial problems made clinician ignore all the worries about relapse caused by over-rescue. This study aims to establish a model for predicting MTX toxicity, as well as to provide an accurate indicator for leucovorin rescue. Currently, no population model regarding predicting MTX toxicity by MTX levels has been established in Chinese childhood ALL.

As above mentioned, the MTX levels at different time points could be used as predictor and indicator. The sample may need to be taken at a time point longer than $66 \mathrm{~h}$ even $90 \mathrm{~h}$, thus the lower limit of MTX assay should be less than $0.05 \mu \mathrm{mol} / \mathrm{L}$. However, the detection range of commercial kit (Siemens VIVA-E) is 0.3 to $2600 \mu \mathrm{mol} / \mathrm{L}$ in China. It is insufficient to find out the correlation between lower MTX levels and toxicities. In 
this single center study, we retrospectively evaluated the MTX levels at different time points and adverse events to identify the predictors of delayed clearance and toxicities in Chinese childhood ALL (Radhakrishnan et al., 2015; Arico, Schrappe, Hunger, 2010) using a modified enzyme multiplied immunoassay technique (EMIT) assay with a new range from 0.05 to $1000 \mu \mathrm{mol} / \mathrm{L}$.

\section{MATERIAL AND METHODS}

This study included 882 samples which were taken from 198 patients with 303 infusions, average 3 samples for each infusion, from January 2012 to December 2017 in Dalian Children's Hospital. Among these patients, the median age was 6.5 years (1-18 years), male $103(52 \%)$ and female 95 (48\%). The patients were stratified into three risk groups, low-, standard-, and high-risk, according to the following criteria. (1) Low-risk group (LR): B-cell precursor ALL with DNA index $\geq 1.16$, TEL-AML1 fusion, or age 1 to 9.9 years and presenting $\mathrm{WBC}<50 \times 109 / \mathrm{L}$. Must not have: CNS 3 status $(\geq 5 \mathrm{WBC} / \mu \mathrm{L}$ of cerebrospinal fluid with morphologically identifiable blasts or cranial nerve palsy); Poor early response ( $\geq 1 \%$ lymphoblasts on day 15 of remission induction, $\geq 0.01 \%$ lymphoblasts by immunologic or molecular methods on remission date).(2) Standard-risk group (SR): The patients were classified as neither LR or HR group. (3)High-risk group (HR): $\mathrm{t}(9,22)$ or BCR-ABL fusion; induction failure or $\geq 1 \%$ leukemic lymphoblasts in the bone marrow on remission date; $\geq 0.1 \%$ leukemic lymphoblasts in the bone marrow in week 7 of continuation treatment; reemergence of leukemic lymphoblasts by MRD in patients previously MRD negative; persistently detectable MRD at lower levels.

In LR group, there were 98 patients with 136 infusions; in SR group, 88 patients with 112 infusions; in HR group, 20 patients with 55 infusions. During the observation, 8 patients in LR group were classified into SR/HR group according to the positive minimal residual leukemia at the end of induction (Harrison, 2015).

The dosage of HDMTX was determined by the risk classification. In SR and HR groups, the patients received $5 \mathrm{~g} / \mathrm{m}^{2}$ MTX, while in LR group, they received $3 \mathrm{~g} / \mathrm{m}^{2}$. HDMTX were administered over $24 \mathrm{~h}$ intravenously. $10 \%$ of the total dose was administered as a loading dose over 1 hour and the remainder took 23 hours. Sodium bicarbonate may be given intravenously at 1 $\mathrm{gm} / \mathrm{m}^{2}$ every 6 hours with pre-hydration fluid beginning from the day before HDMTX administration.
The following items were recorded: Gender, risk classification, details of HDMTX administration (such as dosage, dosage of leucovorin, complete blood counts, kidney function, and serum potassium), as well as toxicity such as mucositis, neutropenia, myelotoxicity, hepatotoxicity, and neurotoxicity. (Godefroid et al., 2014) Toxicity was graded according to the Common Terminology Criteria for Adverse Events (CTCAE) 2010 criteria. (May et al., 2014)

It was defined that MTX should have been cleared thoroughly when the MTX level $<0.1 \mu \mathrm{mol} / \mathrm{L}$ at $66 \mathrm{~h}$, or $<0.05 \mu \mathrm{mol} / \mathrm{L}$ at $90 \mathrm{~h}$. Those had not been cleared thoroughly before $66 \mathrm{~h}$ were defined "delayed clearance". The MTX levels at $42 \mathrm{~h}$ were used as predictor for the clearance at $66 \mathrm{~h}$, while the levels at $42 \mathrm{~h}$ and $66 \mathrm{~h}$ were predictor for toxicities.

ROC (Receiver Operating Characteristic) curve was used to detect the positive predictive value and corresponding sensitivity of delayed clearance and toxicity of MTX. MedCalc (ver. 15.6.1) software was selected for statistical analysis.

The MTX level was measured using Siemens VIVA-E. In China market, the detection range of MTX provided by Siemens assay kit was 0.3 to 2600 $\mu \mathrm{mol} / \mathrm{L}$. We modified the range through the following procedures. An open channel on the VIVA-E was programmed to decrease the volumes of reagents from $180 \mu \mathrm{L}$ to $110 \mu \mathrm{L}$. A six-point calibration curve was programmed with modified cubic spline regression. The original calibrator set $(0,0.20,0.50,1.00,1.50$ and $2.00 \mu \mathrm{mol} / \mathrm{L}$ ) was changed to $0,0.05,0.10,0.25$, $0.50,1.00 \mu \mathrm{mol} / \mathrm{L}$, the new detection range vary from 0.05 to $1000 \mu \mathrm{mol} / \mathrm{L}$. Samples over $1.00 \mu \mathrm{mol} / \mathrm{L}$ should be diluted into the scope of calibration curve (0.05-1.00 $\mu \mathrm{mol} / \mathrm{L})$ using dilution factor 10,100 or 1000 . Method comparison was performed among modified EMIT assay, LC-MS/MS (liquid chromatography-tandem mass spectrometry) assay and commercial EMIT assay (Hyman et al., 1965).

\section{RESULTS}

\section{Prediction of delayed clearance}

MTX was cleared thoroughly in 49 infusions $(16 \%)$ at $42 \mathrm{~h}$, in 228 infusions (75\%) at $66 \mathrm{~h}$, and in 23 $(7 \%)$ infusions at $90 \mathrm{~h}$. The longest time for thorough clearance was $186 \mathrm{~h}$. Averagely 5 doses of leucovorin rescue were administrated in each infusion. 
Delayed clearance was correlated to the dosage of MTX. It occurred in 13\% (22/167) of patients received $5 \mathrm{~g} / \mathrm{m}^{2}$, while it only occurred in 3\% (4/136) of patients received $3 \mathrm{~g} / \mathrm{m}^{2}$ (Pui et al., 2011). No significant difference in pharmacokinetics was observed between males and females. The detailed information of MTX levels at different time points were recorded in Table
I. As Figure 1 shown, the ROC curve was prepared to evaluate the relation between the MTX level at $42 \mathrm{~h}$ and delayed clearance. The optimal cut-off for predicting delayed clearance was $1.5 \mu \mathrm{mol} / \mathrm{L}$ at $42 \mathrm{~h}$ with sensitivity of $82.17 \%$, for predicting thorough clearance was $0.76 \mu \mathrm{mol} / \mathrm{L}$ at $42 \mathrm{~h}$ with sensitivity of $90.78 \%$.

TABLE I - The Risk groups and methotrexate levels at different time points

\begin{tabular}{lcccc}
\hline $\begin{array}{l}\text { Groups } \\
\left.\text { Patients, infusion }^{c}\right)\end{array}$ & $\mathbf{4 2 h}<\mathbf{0 . 8} \boldsymbol{M M}$ & $\mathbf{6 6 h}<\mathbf{0 . 1} \boldsymbol{\mu M}$ & $\mathbf{9 0 h}<\mathbf{0 . 0 5 \mu M}$ & $\begin{array}{c}>\mathbf{9 0 h} \\
<\mathbf{0 . 0 5} \boldsymbol{\mu M}\end{array}$ \\
\hline $\operatorname{LR}(98,136)$ & 46 & 86 & 4 & \\
$\operatorname{SR}\left(82+6^{\mathrm{a}}, 112\right)$ & 3 & 107 & 2 & $3^{\mathrm{b}}$ \\
$\mathrm{HR}\left(18+2^{\mathrm{a}}, 55\right)$ & & 35 & 17 & \\
\hline
\end{tabular}

LR: Low-Risk, SR: Standard-Risk, HR: High-Risk.

a. Eight patients in LR group were classified into SR/HR group provisionally, according to the positive minimal residual leukemia at the end of induction.

b. The MTX clearance of three infusions from different patients were delayed significantly, the longest time of clearance was 186 hours.

c. In LR group, dosage of MTX was $3 \mathrm{~g} / \mathrm{m}^{2}$, while it was $5 \mathrm{~g} / \mathrm{m}^{2}$ in $\mathrm{SR} / \mathrm{HR}$ group.

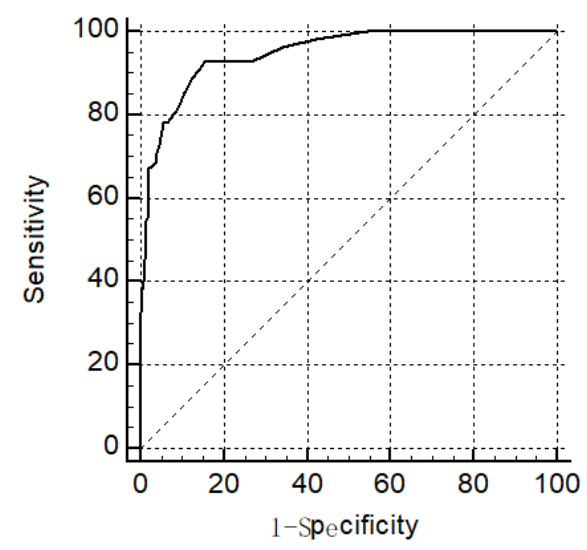

FIGURE 1 - ROC curve was used to evaluate $42 \mathrm{~h}$ Methotrexate level as the predictor of delayed Methotrexate clearance. The Area under Curve (AUC) is $0.880, \mathrm{P}<0.001$, indicates good accuracy in predicting delayed clearance. The optimal cut-off for predicting delayed clearance was $1.5 \mu \mathrm{mol} / \mathrm{L}$ at $42 \mathrm{~h}$ with a sensitivity of $82.17 \%$, that for predicting thorough clearance was $0.76 \mu \mathrm{mol} / \mathrm{L}$ at $42 \mathrm{~h}$ with a sensitivity of $90.78 \%$.

\section{Prediction of MTX toxicity}

The commonest observed toxicity was mucositis in 56 infusions (18\%) with grade I (38) or II (18), then Neutropenia in 28 infusions (9\%) with grade II, myelotoxicity in 12 infusions (4\%) with grade II (10) or III (2), hepatotoxicity in 10 infusions (3\%) with grade II (6) or III (4). Moreover, neurotoxicity was identified in 5 infusions (1.6\%) with MTX dosage of $5 \mathrm{~g} / \mathrm{m}^{2}$. Transient hemiparesis (Grade III) was observed in three of these 
5 infusions, and the patients recovered within one week. Paraparesis (Grade IV) was observed in the other two infusions, but the patients were transferred to other hospital before recovery. All toxicities were treated with appropriate supports. (Common Terminology Criteria for Adverse Events, 2017).
MTX toxicity occurred in 56\% (94/167) of the infusions in $5 \mathrm{~g} / \mathrm{m}^{2}$ group, and it occurred in $12 \%(17 / 136)$ of the infusions in $3 \mathrm{~g} / \mathrm{m}^{2}$ group. The result of chi-square for categorical comparisons was $\mathrm{P}<0.001$. There was significant difference between $3 \mathrm{~g} / \mathrm{m}^{2}$ and $5 \mathrm{~g} / \mathrm{m}^{2}$ groups in terms of toxicities. The detailed information was shown in Table II.

TABLE II - The MTX dosage and toxicity grade

\begin{tabular}{|c|c|c|c|c|c|}
\hline Toxicities & MTX Dosage (g) & Grade I $\mathbf{I}^{\mathbf{a}}$ & Grade II $^{\mathrm{a}}$ & Grade III $^{\mathrm{a}}$ & Grade IV ${ }^{a}$ \\
\hline \multirow{2}{*}{ Mucositis } & 3 & 9 & & & \\
\hline & 5 & 29 & 18 & & \\
\hline \multirow{2}{*}{ Neutropenia } & 3 & & 3 & & \\
\hline & 5 & & 25 & & \\
\hline \multirow{2}{*}{ Myelotoxicity } & 3 & & 4 & & \\
\hline & 5 & & 6 & 2 & \\
\hline \multirow{2}{*}{ Hepatotoxicity } & 3 & & 1 & & \\
\hline & 5 & & 5 & 4 & \\
\hline \multirow{2}{*}{ Neurotoxicity } & 3 & & & & \\
\hline & 5 & & & 3 & 2 \\
\hline
\end{tabular}

a. The classification of toxicity was made based on the Common Terminology Criteria for Adverse Events (CTCAE) 2010 criteria.



FIGURE 2 - ROC curve was used to evaluate $66 \mathrm{~h}$ Methotrexate level as the predictor of toxicities of Methotrexate. The Area under Curve (AUC) is $0.948, \mathrm{P}<0.001$, indicates good accuracy in predicting toxicities. The optimal cut-off for predicting toxicities was $0.5 \mu \mathrm{mol} / \mathrm{L}$ at $66 \mathrm{~h}$ with a sensitivity of $89.09 \%$, that for predicting no toxicity was $0.1 \mu \mathrm{mol} / \mathrm{L}$ with a sensitivity of $92.73 \%$. 
Another ROC curve as Figure 2 shown was prepared to evaluate the relationship between the MTX level at $66 \mathrm{~h}$ and toxicities. The optimal cut-off for predicting toxicities was $0.5 \mu \mathrm{mol} / \mathrm{L}$ at $66 \mathrm{~h}$ with sensitivity of $89.09 \%$, for predicting no toxicity was $0.1 \mu \mathrm{mol} / \mathrm{L}$ at $66 \mathrm{~h}$ with sensitivity of $92.73 \%$.

\section{Method comparison}

Method comparison was performed by comparing the results of modified EMIT assay with the results from LC-
MS/MS assay or commercial EMIT assay respectively. In the range of $0.05-10.00 \mu \mathrm{mol} / \mathrm{L}$, correlation between the Modified assay and LC-MS/MS was significant $(\mathrm{N}=80, \mathrm{R} 2=0.9968)$. In the range of $0.30-10.00 \mu \mathrm{mol} / \mathrm{L}$, correlation between the Modified assay and Commercial assay was significant as well $(\mathrm{N}=45, \mathrm{R} 2=0.9987)$. As Figure 3 shown, there is almost no difference between the results of these two groups. The value obtained from the modified EMIT assay was reliable.
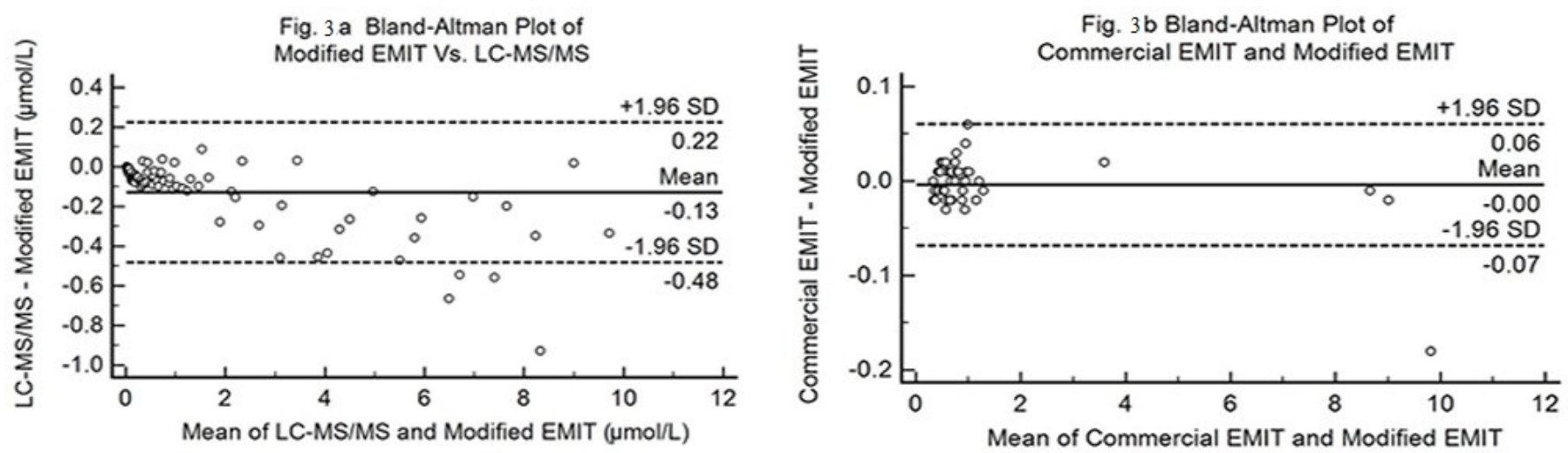

FIGURE 3a - Bland-Altman plot of Modified EMIT and LC-MS/MS measurements. It displays a scatter diagram of the differences between two measurements (Y-axis) against the averages of them (X-axis). Three horizontal lines represent mean, mean+1.96SD and mean-1.96SD. The lines of $\pm 1.96 \mathrm{SD}$ means the limits of agreement.
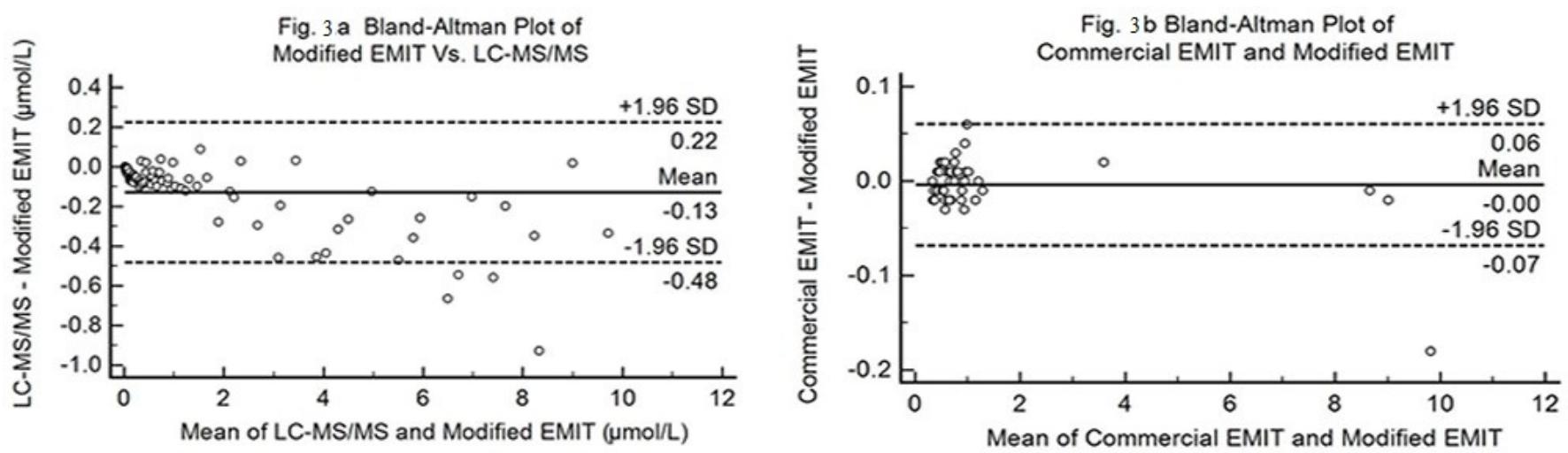

FIGURE 3b - Bland-Altman plot of Modified EMIT and Commercial EMIT measurements.

\section{DISCUSSION}

In this study, we aimed to assess the relationship between toxicity and the MTX levels at $42 \mathrm{~h}$ in children taking different dose of HDMTX. We monitored the
MTX levels at different time points, and observed the corresponding adverse events. Majority of the infusions were well-tolerated, only two Grade IV and nine Grade III events occurred. The incidence of adverse events was correlated with the dosage of MTX and patient's individual 
clearance of MTX. MTX toxicities dramatically decreased in $3 \mathrm{~g} / \mathrm{m}^{2}$ group. In fact, $3 \mathrm{~g} / \mathrm{m}^{2}$ of MTX has become the standard regimen for Pre-B subtype of lymphoblastic leukemia. (Ward et al., 2014) We also found that the MTX level at $42 \mathrm{~h}$ could be used for predicting the delayed clearance of HDMTX. While the MTX level at 66 hours could be used for predicting the toxicities of HDMTX. The level $>1.5 \mu \mathrm{mol} / \mathrm{L}$ at 42 hours or $>0.5 \mu \mathrm{mol} / \mathrm{L}$ at 66 hours indicated the requirement of more frequent monitoring, hydration and leucovorin support.

Since the detection range of commercial kit (Siemens VIVA-E) is $0.3-2600 \mu \mathrm{mol} / \mathrm{L}$ in China, it is insufficient to find out the correlation between lower MTX levels and toxicities. In this study, the modified EMIT assay was applied to detecting MTX levels without any additional instrument, reagent, time or cost. In fact, it reduces about $30 \%$ of the cost. Furthermore, we verified the reliability of the modified assay. In the range of 0.05 $10.00 \mu \mathrm{mol} / \mathrm{L}$, correlation between the Modified assay and LC-MS/MS was significant $(\mathrm{N}=80, \mathrm{R} 2=0.9968)$. In the range of $0.30-10.00 \mu \mathrm{mol} / \mathrm{L}$, correlation between the Modified assay and Commercial assay was significant as well $(\mathrm{N}=45, \mathrm{R} 2=0.9987)$.

However, the available data in our study was limited, we were unable to evaluate the clearance kinetics of MTX on the long-term outcomes and disease relapse patterns. (Den Boer et al., 2009) Additionally, the genetic polymorphisms in folate-metabolizing enzymes may promote the therapeutic effectiveness and reduce the toxicity of MTX (Mahoney et al., 1998), but our study did not included any genetic data of the ALL patients. Thus, further studies about genetic information may be needed.

Therapeutic drug monitor has become a routine clinical test for many years. However, it is very difficult to establish an integrated population pharmacokinetics or pharmacodynamics model with the monitoring results from one institution. That results in low efficiency in data research. (Moriyama, Relling, Yang, 2015)In this study, ROC curve was applied to predict the pharmacokinetics parameters of MTX by integrating the dispersed data from different patients. Finally, we developed a meaningful criterion which is beneficial to the rational and safety use of MTX. This method may also provide references for pharmaceutical research or clinical problems.

\section{CONFLICTS OF INTERESTS}

The authors declare no conflicts of interests.

\section{FUNDING STATEMENT}

The study is supported by grants from Dalian Municipality Medical Research Project (No.1611056).

\section{AUTHOR CONTRIBUTIONS STATEMENT}

Z. Li is the corresponding author, Xiaoping Shi and Hui Gao contributed to this work equally, so they are co-first authors. Zhong Li, Xiaoping Shi and Hui Gao designed the study and analyzed all data, Yang Liu, Lujuan Li, Jinghua Li and Qi Zhang measured all samples and recorded all values. All authors reviewed the manuscript and agreed to publish in this journal.

\section{REFERENCE}

Arico M, Schrappe M, Hunger SP. Clinical outcome of children with newly diagnosed Philadelphia chromosome positive acute lymphoblastic leukemia treated between 1995 and 2005. J Clin Oncol, 2010;28(31):4755-61.

Bouquie R, Deslandes G, Bernaldez BN. A fast LC-MS/MS assay for methotrexate monitoring in plasma: validation, comparison to FPIA and application in the setting of carboxypeptidase therapy. Anal Methods. 2013;6:178-186.

Common terminology criteria for adverse events (CTCAE) - CTCAE_4.03_201006-14_QuickReference_5x7.pdf. 2017 Apr 10. Available from: https://www.eortc.be/services/doc/ ctc/CTCAE_4.03_2010-06-14_QuickReference_5x7.pdf.

Den Boer ML, van Slegtenhorst M, De Menezes RX, Cheok MH, Buijs-Gladdines J, Peters S, et al. A subtype of childhood acute lymphoblastic leukemia with poor treatment outcome: a genome-wide classification study. Lancet Oncol. 2009;10(2):125-34.

Godefroid MJ, von Meyer A, Parsch H, Streichert T, Verstraete AG, Stove V. Multicenter method evaluation of the ARKTM Methotrexate immunoassay. Clin Chem Lab Med. 2014;52(2):e13-16.

Harrison CJ. Blood Spotlight on iAMP21 acute lymphoblastic leukemia (ALL) a high-risk pediatric disease. Blood. 2015;125(9):1383-6.

Hyman CB, Bogle JM, Brubaker CA, Williams K, Hammond D. Central nervous system involvement by leukemia in children. I. Relationship to systemic leukemia and description of clinical and laboratory manifestations. Blood. 1965;25(1):1-12. 
Retrospective evaluation and prediction of clearance and toxicity of high dose methotrexate in childhood acute lymphoblastic leukemia patients

Mahoney DH, Shuster JJ, Nitschke R, Lauer SJ, Steuber $\mathrm{CP}$, Winick N, et al. Acute neurotoxicity in children with B-precursor acute lymphoid leukemia: an association with intermediate-dose intravenous methotrexate and intrathecal triple therapy: a Pediatric Oncology Group study. J Clin Oncol. 1998;16(5):1712-22.

May J, Carson KR, Butler S, Liu W, Bartlett NL, WagnerJohnston ND. High incidence of methotrexate associated renal toxicity in patients with lymphoma: a retrospective analysis. Leuk Lymphoma. 2014;55(6):1345-9.

Moriyama T, Relling MV, Yang JJ. Inherited genetic variation in childhood acute lymphoblastic leukemia. Blood. 2015;125(26):3988-95.

Pui CH, Evans WE. Treatment of acute lymphoblastic leukemia. New England J Med. 2006;354(2):166-178.
Pui CH, Carroll WL, Meshinchi S, Arceci RJ. Biology, risk stratification, and therapy of pediatric acute leukemias: an update. J Clin Oncol. 2011;29(5):551-65.

Radhakrishnan V, Gupta S, Ganesan P, Rajendranath R, Ganesan TS, Rajalekshmy KR, et al. Acute lymphoblastic leukemia: a single center experience with Berlin, Frankfurt, and Munster-95 protocol. Indian J Med Paediatr Oncol Off. 2015;36(4):261-4.

Ward E, DeSantis C, Robbins A, Kohler B, Jemal A. Childhood and adolescent cancer statistics. Cancer J Clin. 2014;64(2):83-103.

Received for publication on $26^{\text {th }}$ July 2018 Accepted for publication on $14^{\text {th }}$ November 2018 